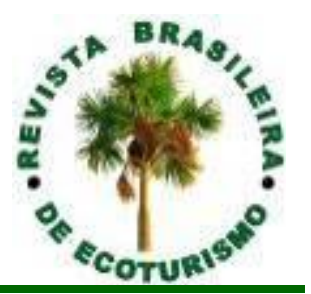

\title{
Uma proposta de valoração do turismo de mergulho e surf nas Unidades de Conservação marinhas do Arquipélago de Fernando de Noronha (PE)
}

\section{A proposal for valuing diving and surf tourism in the marine protected areas of the Fernando de Noronha Archipelago} (PE, Brazil)

José Martins da Silva-Júnior, Lume Garcia Monteiro de Souza, Flávia Queiroz Weysfield, Mariana Andrade Martins, Flávio José de Lima Silva

RESUMO: O turismo vem crescendo nas últimas décadas assim como a visitação a Unidades de Conservação (UCs). O incremento do turismo em UCs pode ajudar economicamente a região a se estruturar e investir na conservação. É fundamental realizar estudos para identificar o perfil do turista que visita as UCs, principalmente quanto à sua consciência ambiental. O ecoturismo, turismo de esportes e o de aventura têm grande potencial de serem atividades turísticas sustentáveis. Desta maneira, o presente estudo tem como objetivo realizar a valoração do turismo de surf e mergulho em Fernando de Noronha. A metodologia usada foi o método custo de viagem. Foram realizadas análises de dados pretéritos, metadados e de entrevistas com surfistas e mergulhadores visitantes no ano de 2019. Foi verificado que esse público é composto majoritariamente por adultos jovens com alto valor aquisitivo. Os gastos médios totais das viagens dos surfistas e dos mergulhadores foram $R \$ 7.912,47$ e $R \$ 8.331,34$, respectivamente. Os principais gastos para surfistas e mergulhadores foram com hospedagem, passagem e alimentação. Os gastos com mergulho representaram apenas $8 \%$ do total da viagem dos mergulhadores e foi 0 gasto com maior nível de satisfação. Já para os surfistas, o gasto que mais valeu a pena foi com o aluguel de automóvel (12\% do total da viagem) para levar seus equipamentos a diversas praias. Outros gastos com alto nível de satisfação foram os relacionados ao contato com a natureza, como passeio de barco e canoa havaiana. Foi perceptível, que esse público injeta significativo capital na ilha. Desta maneira, fica claro que este público tem potencial em auxiliar na manutenção de um turismo econômico e ambientalmente sustentáveis, desde que também sejam oferecidos cursos de formação para prestadores de serviços turísticos e orientações para visitantes, para que o surf e mergulho não se tornem predatórios.

PALAVRAS CHAVE: Ecoturismo Marinho; Economia do Turismo; Turismo Esportivo; Gestão Costeira.

Sociedade Brasileira de Ecoturismo. Rua Dona Avelina, 225, Vila Mariana, São Paulo, SP, Brasil 239 E-mail: zneiman@gmail.com; Tel. (55-11) 99195-7685. 
ABSTRACT: Tourism has been growing in the last decades, as well as visits to Conservation Units (UCs). The increase in tourism in UCs can economically help the region to structure itself and invest in conservation. It is essential to carry out studies to identify the profile of the tourist who visits the UCs, mainly regarding their environmental awareness. Ecotourism, sports tourism, and adventure tourism have great potential to be sustainable tourist activities. In this way, the present study has the objective of valuing surf and diving tourism in Fernando de Noronha. The methodology used was the travel cost method. Analyzes of past data, metadata and interviews with visiting surfers and divers were carried out in 2019. It was verified that this public is composed mainly of young adults with high purchasing value. The total average expenses of trips by surfers and divers were $R \$ 7,912.47$ and $\mathrm{R} \$ 8,331.34$, respectively. The main expenses for surfers and divers were for lodging, passage, and food. Spending on diving represented only $8 \%$ of the divers' total trip and was the expense with the highest level of satisfaction. For surfers, the most worthwhile expense was car rental (12\% of the total trip) to take their equipment to different beaches. Other expenses with a high level of satisfaction were those related to contact with nature, such as boat trips and Hawaiian canoe. It was noticeable, that this public injects significant capital on the island. In this way, it is clear that this public has the potential to assist in the maintenance of economically and environmentally sustainable tourism, provided that training courses are also offered for tourism service providers and guidance for visitors, so that surfing and diving do not become predatory.

KEYWORDS: Marine Ecotourism; Tourism Economics; Sports Tourism; Coastal Management.

\section{Introdução}

O turismo vem se mostrando como um fenômeno social e econômico em expansão no mundo desde o período pós II Guerra Mundial (BRUMATTI, 2013) e não há uma definição única do turismo. Para a Organização Mundial do Turismo (OMT, 2001), por exemplo, viagens a trabalho podem ser consideradas turismo, enquanto alguns autores, como Trigo (1998) e Cooper et al. (2001), defendem que o turismo está mais ligado ao conjunto de fatores que proporcionem experiência de viagem geralmente não relacionadas a atividades remuneradas. No entanto, é fato que, nas últimas décadas, o turismo vem se expandindo e diversificando. Segundo Cooper et al. (2001), o turismo pode ser compreendido com o uma atividade de múltiplas facetas e dimensões.

Desde a década de 1950 houve aumento abrupto do turismo e mais ainda da busca por ambientes naturais. Como resultado do crescimento do turismo houve diversos impactos em vários setores da sociedade, como o acúmulo de riqueza, a exploração de trabalho, segregação de espaços e degradação ambiental (CORIOLANO, 2007).

Desta maneira, na medida em que ecoturismo gera renda, ele também influi na teia social e explora os recursos naturais da localidade. 
Para compensar este efeito negativo, é necessário investimento para conservação ambiental e para manutenção da qualidade de vida dos moradores do destino turístico, e consequentemente manutenção da própria atividade ecoturística. Em um turismo saudável, é necessário que haja sustentabilidade econômica, social e ambiental, uma vez que a busca daquela localidade pelo próprio turismo está diretamente relacionada à disposição de recursos naturais.

Neste contexto, surge o ecoturismo na década de 1970. Segundo a última edição do livreto do Ministério do Meio Ambiente sobre Orientações Básicas de Ecoturismo (BRASIL, 2010), esse seguimento se originou no país a partir de movimentos ambientalistas e da preocupação com 0 desenvolvimento econômico, a degradação do meio ambiente e questões sociais.

Este segmento tem como princípio propor critérios ecológicos para a atividade do turismo que garanta a conservação ambiental juntamente com o envolvimento da comunidade local. Ele tem como principal objetivo proteger recursos naturais, sociais e culturais (BRASIL, 2010; SOCIETY, 2015).

Existem três pilares do turismo que devem se relacionar de forma equilibrada e harmônica para a atividade turística seja sustentável em longo prazo e que ocorra satisfação dos turistas, sendo eles, as ações operacionais, a organização estrutural e as relações ambientais. Nesta última leva-se em consideração tudo que deriva do ambiente externo como questões ecológicas e sociais (BRUMATTI, 2013; FERNANDES; COELHO, 2002; BENI, 1998).

Segundo a União Internacional para Conservação da Natureza (UICN), um turismo sustentável em áreas protegidas deve ocorrer de forma que contribua em longo prazo para a conservação da natureza e não apenas de forma pontual (LEUNG et al., 2019).

Alguns autores, como Dias e Vital (2014), explanam algumas diferenças entre ecoturismo e turismo de aventura. Porém, as definições desses segmentos do turismo parecem divergir entre diferentes autores, 0 que dificulta um planejamento eficiente. Isso ocorre porque, muitas vezes, esses segmentos se relacionam, como é o caso do ecoturismo, turismo de aventura e turismo de esportes praticados na natureza. No entanto, é consenso que estes segmentos ocorrem em meios naturais e exigem, em algum nível, esforço físico dos participantes (ALVES et al., 2016).

Desta maneira, o mergulho e o surf realizados por visitantes em Fernando de Noronha se enquadram nos seguimentos do turismo de esporte, de aventura e ecoturismo.

Existem inúmeros estudos sobre valoração ambiental, como Mendelsohn (2019), Bamwesigye (2019), Guijarro e Tsinaslanidis (2020). Bishop e Boyle (2019) definem "método de valoração" como um conjunto amplamente definido de procedimentos usados para estimar valores fora do mercado. Os exemplos incluem os métodos de avaliação contingente, experimento de escolha, custo de viagem e preço hedônico. 
Silva-Jr. (2003), ao levantar a importância econômica do Parque Nacional Marinho de Fernando de Noronha, pelo método custo de viagem, relata que $R \$ 25.419 .060,00$ (vinte e cinco milhões, quatrocentos e dezenove mil e sessenta reais) foram injetados na economia de Fernando de Noronha em 2002, resultante direta ou indiretamente do turismo no Parnamar-FN.

O presente trabalho tem como objetivo apresentar alguns elementos que possam colaborar com a futura valoração do turismo de surf e mergulho em Fernando de Noronha, expondo algumas as vantagens e desvantagens para a sustentabilidade econômica e ambiental destas atividades para 0 Arquipélago.

\section{Caracterização da área de estudo}

O Arquipélago de Fernando de Noronha é um distrito do Estado de Pernambuco situado no Oceano Atlântico, a $345 \mathrm{~km}$ de Natal-RN região da costa brasileira mais próxima (Figura 1). O Arquipélago possui uma área terrestre com $26 \mathrm{~km}^{2}$ em 17 ilhas secundárias. A ilha principal possui 17,6km² de área e é separada em duas faces (SILVA-Jr, 2010).

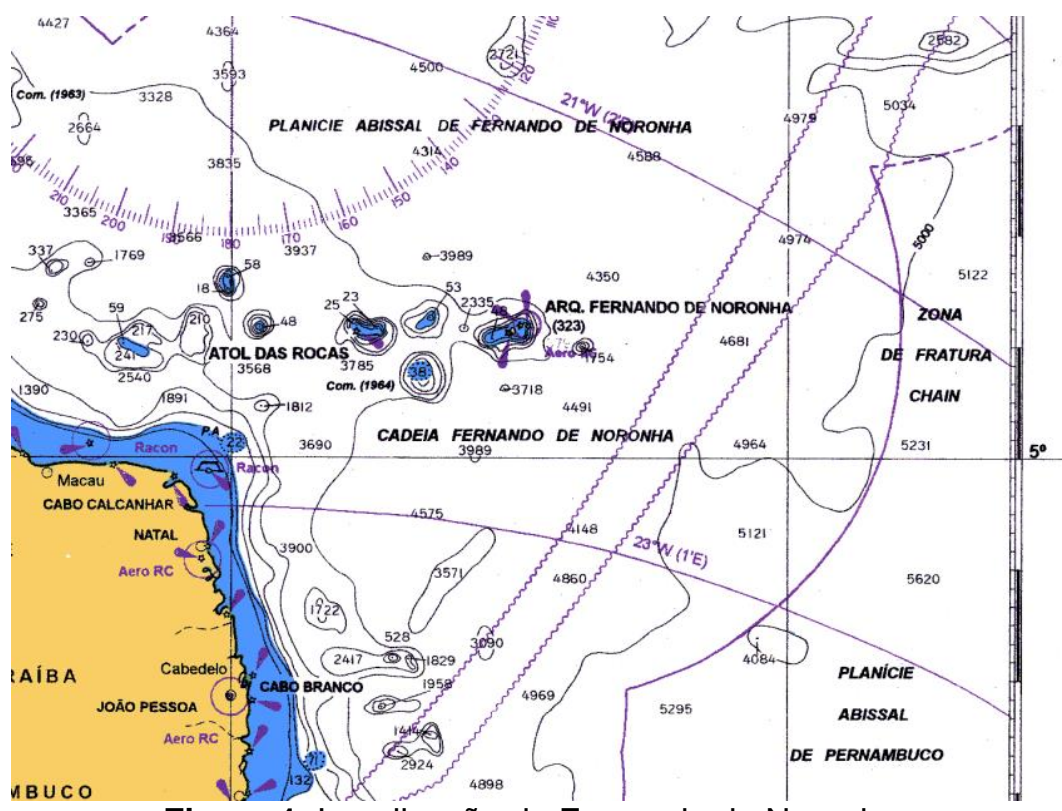

Figura 1: Localização de Fernando de Noronha.

Figure 1: Location of Fernando de Noronha

Fonte: DHN / Marinha do Brasil.

Source: DHN / Brazilian Navy.

A face noroeste é conhecida como Mar de Dentro por ser mais abrigada dos ventos predominantes e predominar condições de mar tranquilo, permitindo a deposição de areias nas praias. A face do lado oposto do Arquipélago é conhecida como Mar de Fora, sofre grande influência dos ventos predominantes sul e sudeste e se caracteriza por possuir encostas mais íngremes, mar mais agitado e costa predominantemente rochosa.

Todo o Arquipélago, tanto em terra como nas águas que o circulam, está inserido dentro de duas Unidades de Conservação (UC) de categorias 
distintas. O Parque Nacional Marinho de Fernando de Noronha (ParnamarFN) é uma UC de proteção integral, com uso mais restritivo. A área de Preservação Ambiental de Fernando de Noronha - Rocas - São Pedro e São Paulo (APA-FN) é uma UC de uso sustentável, que permite mais atividades antrópicas, como moradia, instalações de infraestrutura, agropecuária e pesca (PEREIRA, 2015; TISCHER, 2011; SILVA-Jr., 2010).

Há pontos de mergulho e de surf nas duas UCs, no entanto, os principais pontos de mergulho localizam-se no Parnamar-FN e os principais picos de surf se encontram na área da APA-FN. Vale ressaltar que há épocas do ano mais favoráveis para a execução de cada uma dessas atividades. O surf é praticado quando entram grandes ondulações (swells) do quadrante norte, o que ocorre principalmente entre os meses de dezembro e março. Nessa época, o Mar de Dentro fica mais agitado, dificultando a prática de mergulho, principalmente nos pontos mais rasos.

\section{Material e Métodos}

A metodologia de valoração usada neste trabalho seguiu as mais modernas bibliografias sobre o tema, como He e Poe (2020), Orlowski e Wicker (2019) e Bhat e Bhatt (2019).

Para realizar este estudo amplo e integrado sobre as questões relacionadas ao turismo de surf e mergulho autônomo em Fernando de Noronha, foram feitas análises de dados pretéritos, de metadados e de entrevistas com mergulhadores e surfistas que visitaram a ilha no ano de 2019.

As entrevistas seguiram roteiros semiestruturados com perguntas abertas e fechadas, visando extrair informações quantificáveis, mas que também permitissem uma análise qualitativa. Desta maneira, trata-se de uma pesquisa quali-quantitativa.

Foram elaborados dois diferentes roteiros de entrevistas, sendo um direcionado a mergulhadores visitantes e outro a surfistas visitantes. Desta forma, foram coletadas informações de maneira ampla, que permitem comparação das visões e realidades dos referidos setores do turismo.

As questões foram elaboradas de modo a coletar informações que permitiram traçar, o perfil do turista; as noções de conhecimento acerca do ambiente visitado; além de realizar a valoração destas modalidades de turismos para a área estudada por meio do método "custo da viagem".

A realização das entrevistas ocorreu entre outubro e dezembro 2019 e os entrevistados foram abordados em pontos específicos em que geralmente há maior probabilidade de encontrar esse público, como por exemplo, a praia da Cacimba do Padre (foco de surfistas) e a Praia do Porto (foco de mergulhadores).

Os entrevistados foram escolhidos aleatoriamente pelos pesquisadores. Após a escolha aleatória, era feita a abordagem e o pesquisador se certificava que a pessoa tivesse praticado pelo menos uma 
das atividades esportivas, selecionando desta maneira o público (mergulhadores e surfistas) e descartando público não alvo da pesquisa.

Com os dados obtidos e digitalizados foram realizadas análise de frequência relativa das questões quantificáveis e análise descritiva das questões qualitativas.

\section{Resultados e Discussão}

Ao todo foram realizadas 200 entrevistas, sendo 100 com mergulhadores visitantes e 100 com surfistas visitantes de Fernando de Noronha.

Os dados demonstraram que os visitantes (surfistas e mergulhadores) de Fernando de Noronha pertencem a um grupo de pessoas com alto poder aquisitivo, tendo majoritariamente $(57 \%)$ renda familiar maior que $R \$$ $10.000,00$ mensais (Figura 2). A idade variou de 13 a 63 anos de idade, com média de 35,7 anos (DP $\pm 9,45$ ).

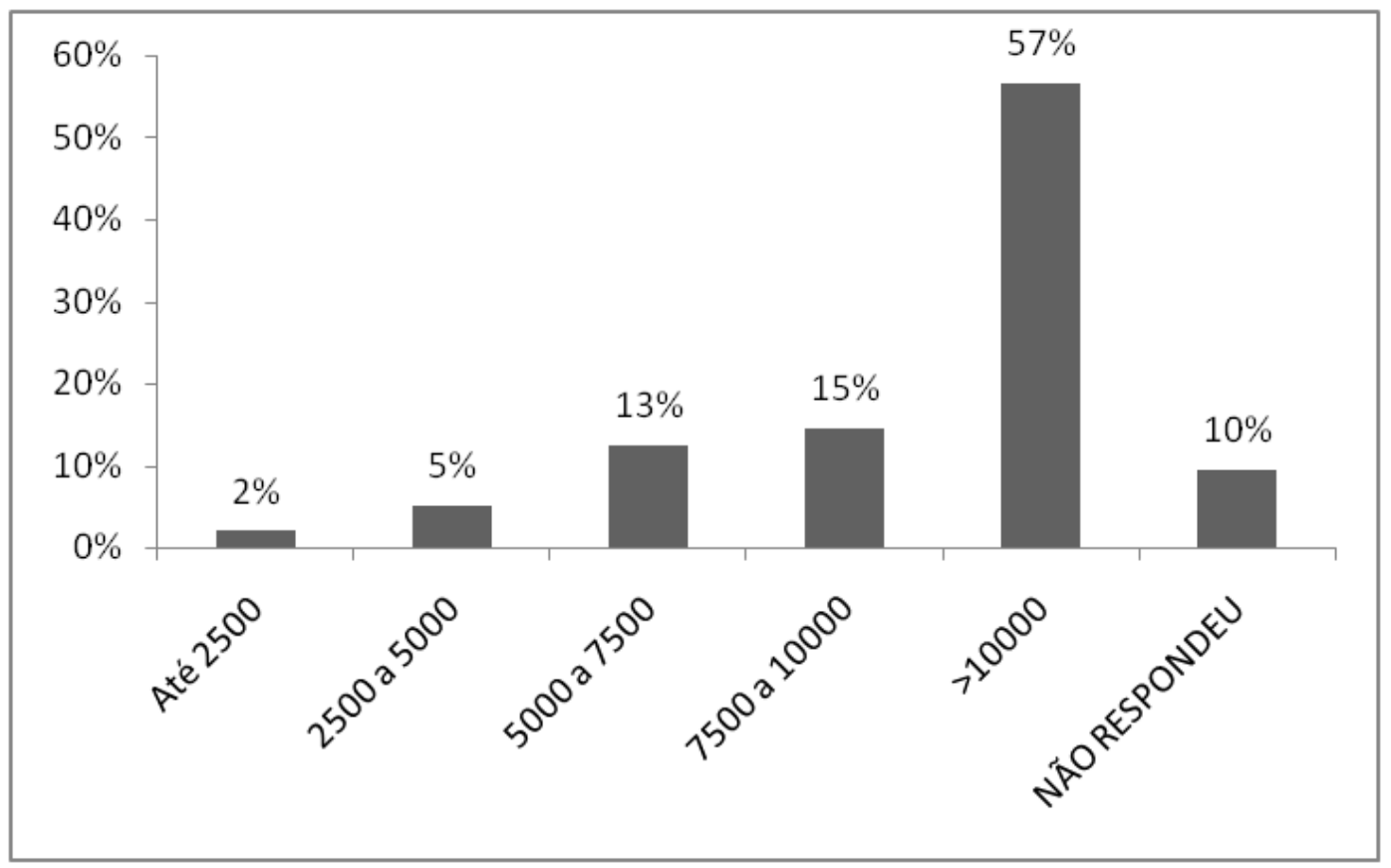

Figura 2: Frequência relativa da renda familiar mensal dos turistas entrevistados. Figure 2: Relative frequency of the monthly family income of the interviewed tourists. Fonte: Elaborado pelos autores.

Source: Prepared by the authors.

Esses dados vão ao encontro com o que Rawe e Santos (2016) encontraram para turistas mergulhadores de todo o mundo, mostrando que os turistas de mergulho tendem a serem jovens e de alto poder aquisitivo. Provavelmente isto deva ao fato de que, tanto para a prática de mergulho quanto de surf, é necessário condicionamento físico, perfil de aventureiro e disponibilidade de tempo e financeira para viajar para lugares distantes. 
O levantamento de custo de viagem demonstrou pouca diferença entre os gastos médios totais das viagens dos surfistas ( $\mathrm{R} \$ 7912,47$; DP $\pm R \$ 5649,29)$ e dos mergulhadores ( $R \$ 8331,34$; $D P \pm R \$ 4165,47)$.

Segundo nosso levantamento, o custo mínimo e máximo da viagem à ilha em 2019 variou entre $R \$ 732,00$ e $R \$ 27000,00$ por pessoa. Vale ressaltar que o menor valor foi o único nesta faixa, pois tratava-se de um surfista que se hospedou em casa de amigo, gastando apenas com passagem. Desta maneira, os turistas de esportes, ao visitarem Noronha injetam considerável quantidade de recursos financeiros na economia local.

De maneira geral, as médias de despesas com cada atividade foram muito próximas entre os dois grupos analisados. Tanto para surfistas quanto para mergulhadores, as maiores despesas foram com hospedagem, passagem e alimentação.

Dos $\mathrm{R} \$ 7912,47$ em média (DP $\pm \mathrm{R} \$ 5649,29$ ) que os surfistas gastam com a viagem para Noronha, $32 \%$ são gasto com hospedagem, $20 \% \mathrm{com}$ passagem e 17\% com alimentação (Figura 3). Enquanto para os $\mathrm{R} \$ 8331,34$ (DP $\pm \mathrm{R} \$ 4165,47$ ) gastos em média com a viagem por mergulhadores, $30 \%$ é gasto com hospedagem, $21 \%$ com passagem e 16\% com alimentação.

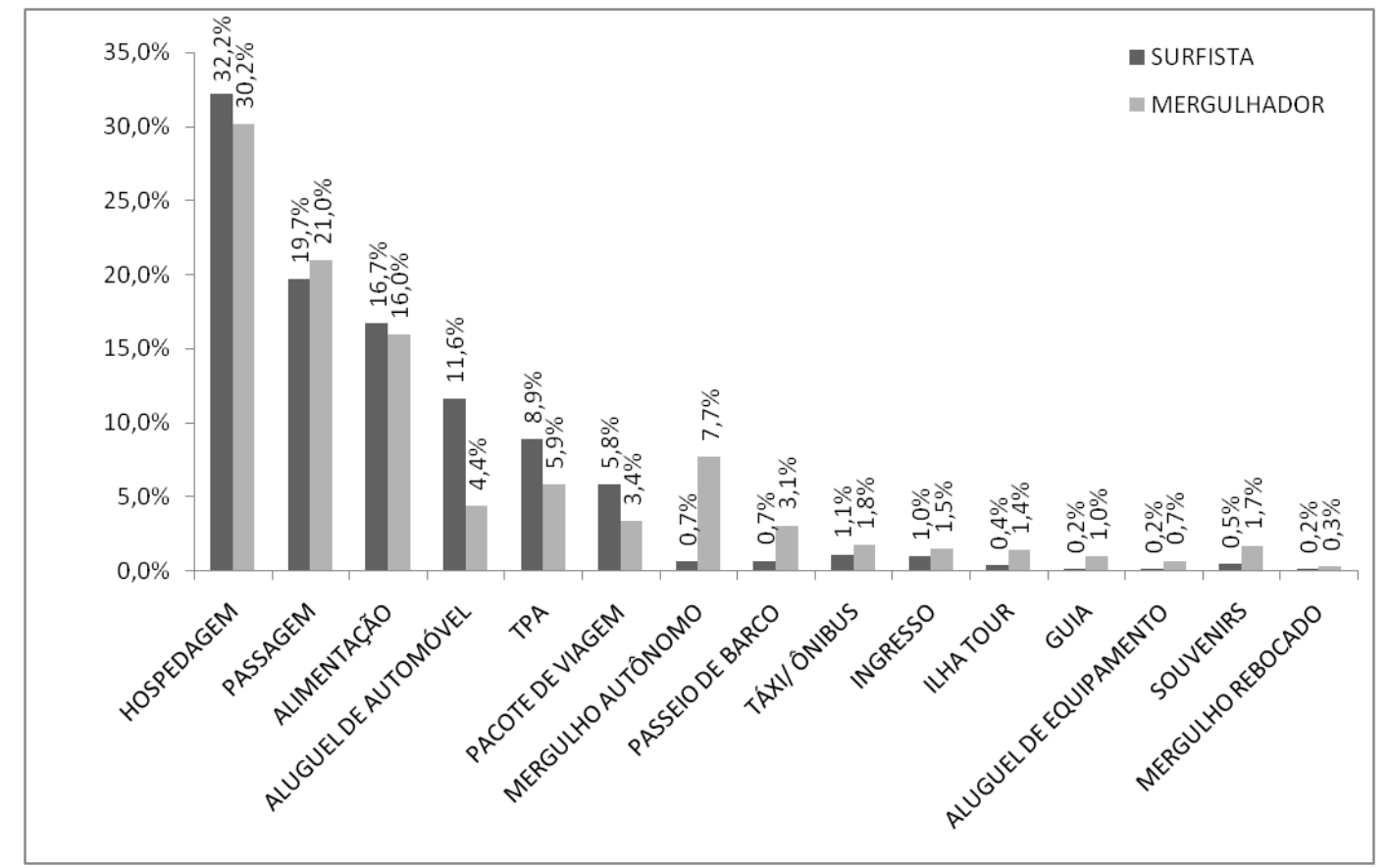

Figura 3: Frequência relativa dos gastos por atividade em relação ao custo médio total da viagem de surfistas e de mergulhadores.

Figure 3: Relative frequency of spending per activity in relation to the total average cost of travel by surfers and divers.

Fonte: Elaborado pelos autores.

Source: Prepared by the authors.

O parâmetro com maior diferença de gastos entre mergulhados e surfistas foi o mergulho autônomo, onde, de maneira esperada, os mergulhadores investem significativamente mais recursos financeiros em 
mergulhos, gastando em média $8 \%$ total da viagem com esta atividade, enquanto os surfistas usam apenas $1 \%$ da média total da viagem para esse fim.

Outros custos que merecem destaque são a Taxa de Preservação Ambiental (TPA), cobrada pelo Estado de Pernambuco a todos os turistas de Fernando de Noronha, e o aluguel de automóvel. Do valor médio total de sua viagem, os surfistas usam em média 9\% com TPA e 12\% com aluguel de carro. Enquanto os mergulhadores usaram, do valor médio total de sua viagem, $6 \%$ com a TPA e $4 \%$ com aluguel de automóvel.

Isso demonstra que o tipo de esporte praticado muda o perfil de gasto do turista. Surfistas dependem de boas ondas para praticarem seu esporte, o que nem sempre é possível encontrar. Permanecer mais tempo na ilha aumenta a probabilidade de pegar boas ondas. Da mesma forma, o transporte de equipamentos de mergulho é feito pela própria operadora contratada enquanto os surfistas necessitam de automóvel para transportar seu equipamento (pranchas), levando esse público a investir mais em meio de transporte.

Moreira et al. (2019) afirmam que 63\% dos turistas que visitam Fernando de Noronha realizam a atividade de mergulho. De acordo com dados públicos divulgados pela ATDEFN, em 2019, Fernando de Noronha teve 106.130 visitantes (não moradores). O custo de um mergulho autônomo na ilha varia de $R \$ 250,00$ a $R \$ 650,00$, com preço médio de é de $R \$ 450,00$. Como já afirmado, 66.862 pessoas realizaram mergulho autônomo em 2019, gerando um capital bruto mínimo de $\mathrm{R} \$ 30.087 .900,00$.

Apesar de representar apenas $8 \%$ do gasto médio total da viagem, $68 \%$ dos turistas mergulhadores citaram o mergulho como um dos gastos que mais valeram apena investir (Figura 4). Esta era uma questão aberta onde o entrevistado possuía liberdade de expressar voluntariamente os custos que mais lhe trouxeram a sensação de que valia o investimento. Desta maneira um mesmo entrevistado poderia citar mais de um investimento.

Como $63 \%$ dos turistas que visitam Noronha realizam atividade de mergulho (MOREIRA, et al. 2019), a satisfação que esse público teve em investir nessa atividade representa garantia de manutenção dessa fonte de renda importantíssima para a Ilha.

Rawe e Santos (2016) e Ince e Bowen (2011) dizem que a relação de satisfação com atividade de mergulho está diretamente relacionada à exclusividade de estar em um local único, praticamente intocável e principalmente com diversidade de vida marinha. Sendo assim, é fundamental a manutenção desse recurso natural, o que só é possível com ações de divulgação, orientação e normatização em prol da conservação marinha.

Já para os surfistas, o gasto considerado com melhor custo/benefício foi o aluguel de automóveis (22\%), o que demonstra que esse público provavelmente continuará a injetar recurso neste setor da economia local. 


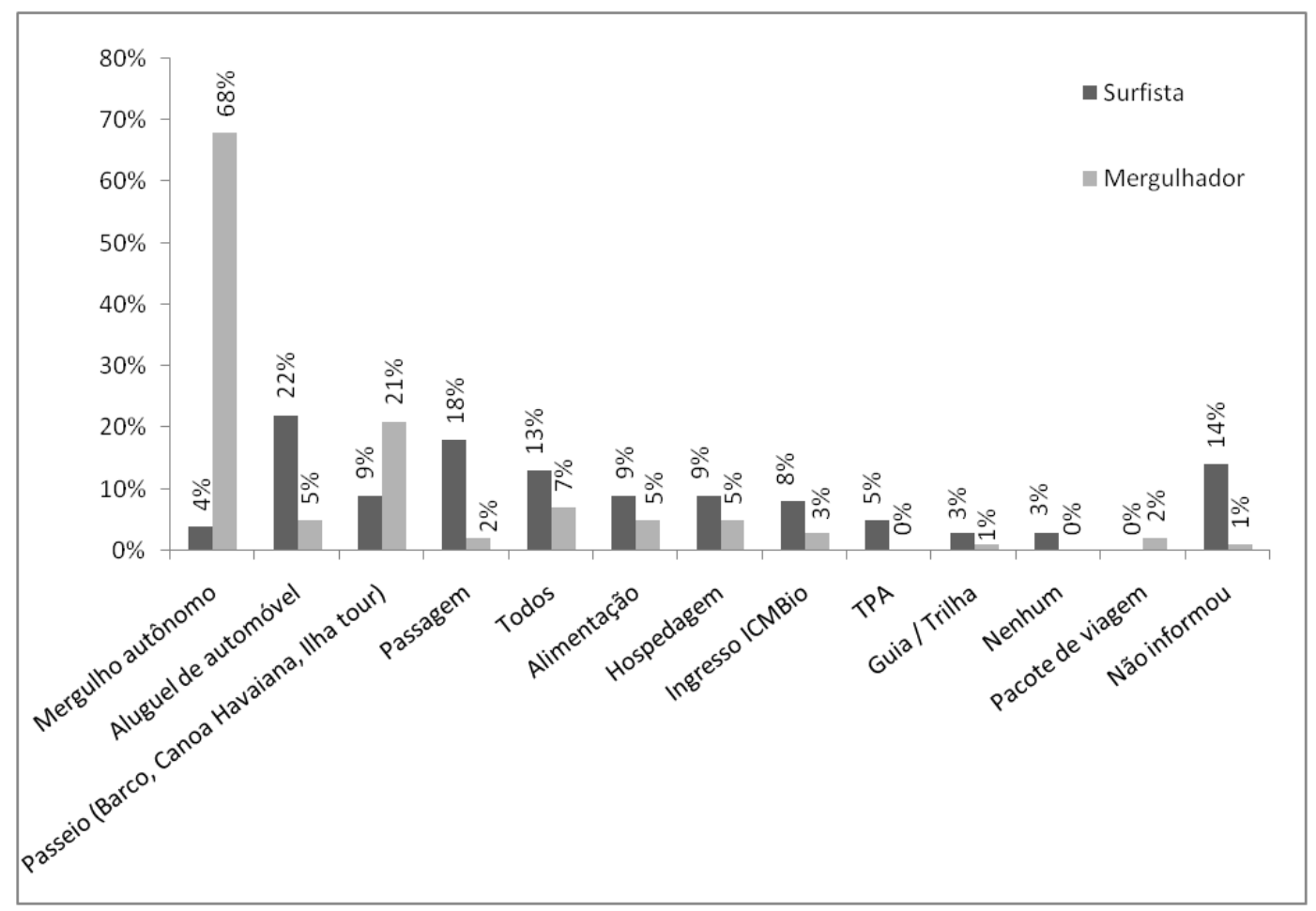

Figura 4: Frequência relativa de surfistas e mergulhadores em relação aos custos que consideram que mais "valem a pena" investir.

Figure 4: Relative frequency of surfers and divers in relation to the costs they consider to be more worthwhile to invest.

Fonte: Elaborado pelos autores.

Source: Prepared by the authors.

Como demonstrado na Figura 4, além da satisfação de gasto com mergulho autônomo e com o aluguel de automóvel, destaca-se também a satisfação do gasto com passeios (barco, canoa havaiana e ilha tour) que são atividades diretamente ligadas aos recursos naturais de Fernando de Noronha.

Diversos estudos (ROWE; SANTOS, 2016; ONG; MUSA, 2012; COTTRELL; MEISEL, 2003; BIZERRA; ZUMPANO, 2017; THAPA et al., 2005) demonstram que turistas de esportes e de ecoturismo, tendem a buscar contato com ambiente natural preservado e que a sensibilização e preocupação com o ambiente aumenta proporcionalmente de acordo com as experiências obtidas nesses tipos de turismo. Frantz e Mayer (2014) e Nisbet e Gick (2008) explicam que essa consciência ambiental advém do sentimento de pertencimento e vínculo com o ambiente através das experiências vivenciadas no contato com o meio natural.

Ao serem questionados sobre o custo que "menos valeu à pena", $25 \%$ dos surfistas e $21 \%$ dos mergulhadores preferiram não informar, enquanto $17 \%$ dos surfistas e $16 \%$ mergulhadores consideraram que nenhum recurso foi mal-empregado, como demonstrado na Figura 5. Os gastos com maiores níveis de insatisfação foram a TPA (20\% dos surfistas e $15 \%$ dos mergulhadores) e a alimentação (13\% dos surfistas e $11 \%$ dos 
mergulhadores). Estas questões eram abertas e permitiam que 0 entrevistado expressasse insatisfação a mais de um gasto.

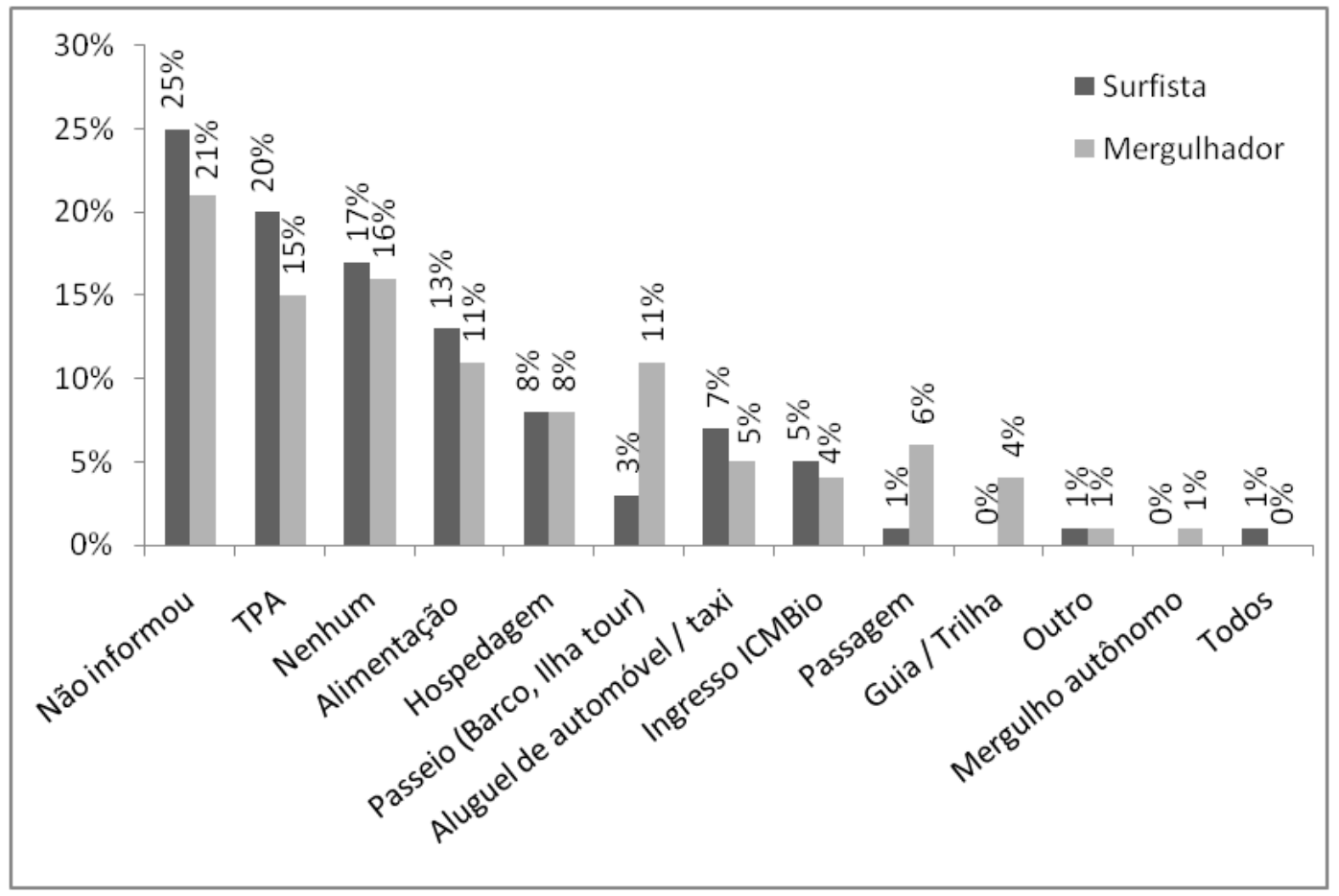

Figura 5: Frequência relativa de surfista e mergulhadores em relação aos custos que consideram que menos "valem a pena" investir.

Figura 5: Relative requirement of surfer and divers in relation to the costs that they consider less "worthwhile" to invest.

Fonte: Elaborado pelos autores.

Source: Prepared by the authors

Além do levantamento do custo da viagem e do nível de satisfação e insatisfação com cada gasto, buscou-se também compreender as principais motivações que levaram aqueles turistas até Fernando de Noronha e a percepção ambiental deles.

Levando em consideração que, geralmente os fatores motivacionais são diversos, permitiu-se que cada entrevistado assinalasse mais de um parâmetro como motivo da viagem e que citassem outros motivos caso fosse pertinente (Figura 6).

Como esperado, para os surfistas o motivo mais vezes apontado foi o surf $(97 \%)$ e para os mergulhadores, o mergulho (76\%). Outro motivo da viagem com grande representatividade foi o Turismo de Sol e Praia, sendo opção de $74 \%$ dos surfistas e de $57 \%$ dos mergulhadores, que é algo esperado, uma vez que esse é um forte atrativo da ilha de Fernando de Noronha. No parâmetro "outros", foram citadas motivações como casamento, lua de mel, trabalho, corrida $21 \mathrm{k}$, conhecer a ilha em geral, família, pesca, belezas naturais, fotografia, ver tubarões e descansar. 


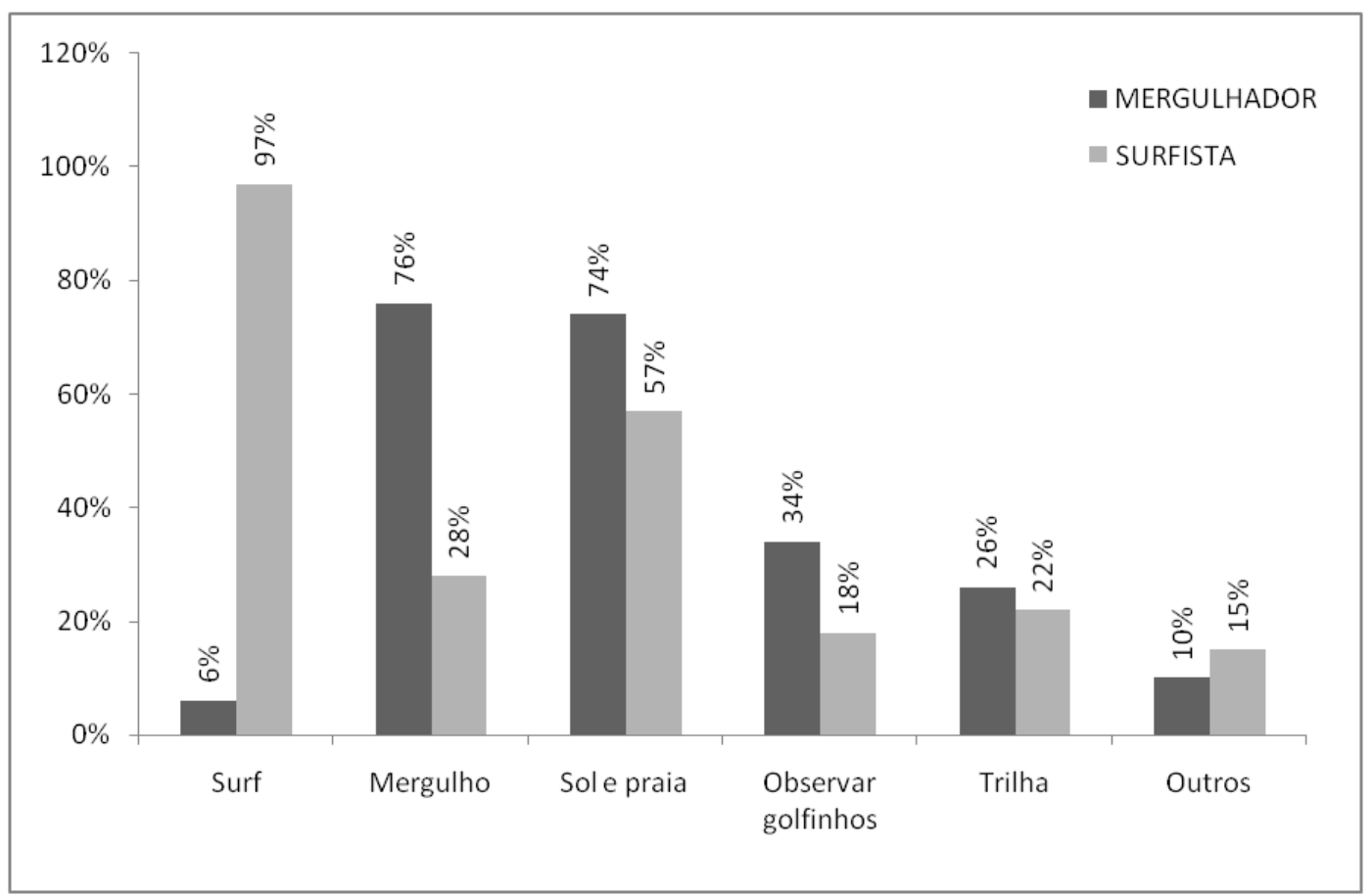

Figura 6: Frequência relativa dos fatores de motivação da viagem à Noronha para mergulhadores e surfistas.

Figura 6: Relative frequency of motivating factors for the trip to Noronha for divers and surfers.

Fonte: Elaborado pelos autores.

Source: Prepared by the authors.

Este estudo revela que os principais atributos motivacionais que atraem turistas para Fernando de Noronha, estão relacionados com a oferta de recursos naturais. Moreira, et al. (2019), mostra que isso não é verdade apenas para o recorte turista de mergulho ou de surf, ao constatar em seu estudo que $71 \%$ dos turistas de Fernando de Noronha declaram que a principal razão de visitar é ilha é "ter contato com a natureza".

A fim de valorar a relevância do mergulho e do surf para um aspecto geral na viagem do turista, foi solicitado que o entrevistado ponderasse, dentre todas as atividades que os proporcionaram satisfação com a viagem, o quanto (em porcentagem) o surf ou mergulho representaram para eles. Dentre todas as atividades realizadas durante a viagem pelos turistas mergulhadores entrevistados, o mergulho foi o principal responsável pela satisfação, sendo responsável por $75,5 \%$ da satisfação total da viagem. Para os surfistas a média foi maior, sendo o surf responsável por $82,8 \%$ da satisfação total com a viagem dos turistas surfistas entrevistados.

Já em relação à percepção ambiental desse tipo de turista, verificouse que a maioria dos entrevistados $(69 \%)$ declarou não conhecer local mais preservado que Fernando de Noronha e 95\% consideraram correta a criação das Unidades de Conservação existentes no Arquipélago, justificando em sua maioria, que a existência dessas unidades são as responsáveis pela preservação do local.

Vale ressaltar que o custo de viagem para Fernando de Noronha está acima da média das viagens para outros destinos nacionais e em alguns 
casos, até internacionais. Os dados aqui apresentados evidenciam que os recursos naturais estão diretamente relacionados com os motivos de atração e satisfação da viagem, justificando os gastos acima da média.

O turismo de surf e de mergulho corresponde a um grande aporte de recursos econômicos na ilha e são esportes que tendem a provocar sensibilização dos turistas em prol da conservação marinha, se houver orientação adequada. Esse perfil de turista é importante para uma economia sustentável, uma vez que tem o potencial de não ser exploratório, mantendo assim os principais atrativos locais.

\section{Considerações Finais}

Como demonstrado, o turismo esportivo em Fernando de Noronha gera volume de recursos financeiros importantes para a comunidade local. Para o mergulhador, a principal motivação de mergulhar é poder entrar em contato com grande variedade de vida em um ecossistema conservado e com excelentes condições de mergulho, possível de ser encontrado em poucos lugares do mundo. Já para os surfistas, o maior atrativo são as características das ondas e as condições ambientais que favorecem um surf confortável e com pouco risco de acidentes, como ataques de tubarões.

Apesar dos custos diretos com os esportes não apresentarem um percentual alto em relação ao custo total da viagem, são eles os principais responsáveis pela satisfação do visitante com a viagem.

O turismo de surf e mergulho movimenta direta e indiretamente milhões de reais ao ano na ilha de Fernando de Noronha e os turistas atraídos para essa modalidade turística possuem alta probabilidade de serem ou se tornarem pessoas ambientalmente conscientes, se a prática do turismo for bem orientada.

O uso sustentável dos recursos naturais auxilia na manutenção de geração de renda para a comunidade local. Sendo assim, o estímulo a esta modalidade de turismo pode auxiliar na sustentabilidade social, econômica e ambiental do turismo em Fernando de Noronha. Entendendo que toda atividade só é sustentável economicamente se também for sustentável socioambientalmente. Só há uma maneira de uma atividade que não tenha sustentabilidade socioambiental ter sustentabilidade econômica, que é por meio da externalidade. Conseguida por meio de subsídios, sonegação de impostos e/ou não computação do custo socioambiental da atividade ao sistema e a sociedade.

\section{Referências}

ALVES, M.S.; DE-BORTOLI, A.L.; KIRST, F.V.; MESSIAS, S.M.C.; DEBORTOLI, R. Normalização do Ecoturismo e Turismo de Aventura no Brasil. Revista Brasileira de Ecoturismo, São Paulo, v.9, n.3, pp.433-444.

BAMWESIGYE, D. Expressed preference methods of environmental valuation: Non-market resource valuation tools. 2019. 
BHAT, M.Y.; BHATT, M. S. Economic Valuation of Dachigam National Park: An Operational Tool for Sustainable Development. In: GUPTA, A.M., DALEI, N.N. (eds). Energy, Environmentand Globalization: Recent Trends, Opportunities and Challenges in India. Springer: Singapore, p. 203-216, 2019.

BISHOP, R.C.; BOYLE, K.J. Reliability and validity in nonmarket valuation. Environmental and Resource Economics, v. 72, n. 2, p. 559-582, 2019.

BENI, M.C. Análise Estrutural do Turismo. São Paulo: Senac, 1998.

BRASIL, Ministério do Turismo. Ecoturismo: orientações básicas. $2^{a}$ Edição - Brasília: Ministério do Turismo, 2010.

BRASIL, Ministério do Turismo. Turismo de Aventura: orientações básicas. $3^{\mathrm{a}}$ Edição - Brasília, 2010.

BRUMATTI, P.N.M. O papel do turismo de observação da vida selvagem para a conservação da natureza. Anais do IX Congresso Nacional de Ecoturismo e do $\mathrm{V}$ Encontro Interdisciplinar de Turismo em Unidades de Conservação. Revista Brasileira de Ecoturismo, São Paulo, v.6, n.4, nov2013, pp.191-206.

COOPER, C.; FLETCHER, J.; WANHILL, S.; GILBERT, D.; SHEPERD, R. Turismo: Princípios e Prática. $2^{\circ}$ ed. Porto Alegre: Bookman, 2001.

CORIOLANO, L.N.M.T. Turismo e meio ambiente: Interfaces e Perspectivas. In: O turismo e a relação sociedade-natureza: realidades, conflitos e resistências. Fortaleza: EdUECE , v. 1, p. 19-43. 2007

COTTRELL, S.P.; MEISEL, C. Predictors of personal responsibility to protect the marine environment among divers. In: NORTHEASTERN RECREATION RESEARCH SYMPOSIUM, 2003, Newtown Square. Proceedings. Department of Agriculture, Forest Service, Northeastern Research Station, p. 252-261, 2003.

DIAS, P.P.; VITAL, T.W. O Ecoturismo no Estado de Pernambuco: uma visão do segmento a partir da oferta de serviços. Revista Turismo em Análise, v. 25, n. 2, p. 316-336, 2014.

FERNANDES, I.P.; COELHO, M.F. Economia do Turismo: teoria e prática. Rio de Janeiro: Elsevier, 2002.

GUIJARRO, F.; TSINASLANIDIS, P. Analysis of the Academic Literature on Environmental Valuation. International Journal of Environmental Researchand Public Health, v. 17, n. 7, p. 2386, 2020.

HE, X.Y.; POE, G.L. Exploring thes helf-life of travel cost methods of valuing recreation for benefits transfer. Resource and Energy Economics, p. 101123, 2020.

INCE, T.; BOWEN, D. Consumers at is faction and services: insights from dive tourism. The Service Industries Journal, v. 31, n. 11, p. 1769-1792, 2011. 
LEUNG, Y.F.; SPENCELEY, A.; HVENEGAARD, G.; BUCKLEY, R. Turismo e gestão da visitação em áreas protegidas. Diretrizes para sustentabilidade. Série Diretrizes para melhores Práticas para Áreas Protegidas No. 27, Gland, Suiça: UICN. xii + 120 pp. 2019.

MENDELSOHN, R. An examination of recent revealed preference valuation methods and results. Review of Environmental Economics and Policy, v. 13, n. 2, p. 267-282, 2019.

MOREIRA, J.C.; HAURA, F.K.; BURNS, R.C.; CAIRES, A.M. Perfil, Percepção dos Visitantes e a Observação de Animais Silvestres: Estudo de Caso do Parque Nacional Marinho de Fernando de Noronha-PE. Revista Anais Brasileiros de Estudos Turísticos-ABET, v. 9, n. 1, 2 e 3, 2019.

OMT. Introdução ao turismo. São Paulo: ROCA, 2001.

ONG, T.F.; MUSA, G. Examining the influences of experience, personality and attitude on SCUBA divers' underwater behaviour: A structural equation model. Tourism management, v. 33, n. 6, p. 1521-1534, 2012.

ORLOWSKI, J.; WICKER, P. Monetary valuation of non-market goods and services: a review of conceptual approaches and empirical applications in sports. European Sport Management Quarterly, v. 19, n. 4, p. 456-480, 2019.

PEREIRA, A.I.A..; SILVA, F.J.L.; SILVA-JÚNIOR, J.M. Influência dos cursos de capacitação do Projeto Golfinho Rotador na atuação profissional dos condutores de ecoturismo em Fernando de Noronha (PE): uma contribuição a sustentabilidade turística local. Revista Brasileira de Ecoturismo, São Paulo, v.8, n.1, pp.31-58. 2015.

PEREIRA, P.J.G. Turismo de Surf: estudo exploratório do perfil e motivações dos consumidores da modalidade em escolas de surf no litoral alentejano. Dissertação de Mestrado. Universidade de Évora. 2019.

ROWE, R.Y.G.; SANTOS, G.E.O. Turismo de mergulho: análise do comportamento de viagem dos mergulhadores brasileiros. Caderno Virtual de Turismo. Rio de Janeiro, v. 16, n. 3, p. 61-75, dez. 2016.

SILVA-JÚNIOR, J.M. Os golfinhos de Noronha. $1^{\circ}$ Edição. São Paulo: Bambu, 2010.

SILVA-JÚNIOR, J.M. Parque Nacional Marinho de Fernando de Noronha: Uso Público, Importância Econômica e Proposta de Manejo. In: Anais do SIMPÓSIO DE ÁREAS PROTEGIDAS CONSERVAÇÃO NO ÂMBITO DO CONE SUL, 2.Pelotas: UCP, 2003.

SOCIETY, The Internatinal Ecoturism. Whatis Ecotourism? Fonte: The International Ecotourism Society: https://www.ecotourism.org/what-isecotourism, 2015. Acesso em 15/03/2020.

TRIGO, L.G.G. Turismo Básico. São Paulo, SP: SENAC, 1998. 


\section{Agradecimentos}

À Petrobras, por meio do Programa Petrobras Socioambiental, ATDEFN e ICMBio Noronha, ANEMA, ASFN e Escola do Mar Alma Solar Noronha. Aos pesquisadores, Vithor Macêdo de Azevedo, Priscila Izabel Alves Pereira de Medeiros, Lisandra Maria de Lima Silva Bezerra, Melyna lyra Pedroso, Carolina Pestana da Silva e Cynthia Gerling de Oliveira pela contribuição na construção deste estudo.

José Martins da Silva-Júnior: Instituto Chico Mendes de Conservação da Biodiversidade, Fernando de Noronha, PE, Brasil.

E-mail: josemartinstk@gmail.com

Link para o currículo Lattes: http://lattes.cnpq.br/1133638779776273

Lume Garcia Monteiro de Souza: Projeto Golfinho Rotador, Fernando de Noronha, PE, Brasil.

E-mail: lumemonteiro@gmail.com

Link para o currículo Lattes: http://lattes.cnpq.br/0935059330805844

Flávia Queiroz Weysfield: Projeto Golfinho Rotador, Fernando de Noronha, PE, Brasil.

E-mail: flaviaqw@gmail.com

Link para o currículo Lattes: http://lattes.cnpq.br/9487576107296212

Mariana Andrade Martins: Projeto Golfinho Rotador, Fernando de Noronha, PE, Brasil.

E-mail: marianailhote@gmail.com

Link para o currículo Lattes: http://lattes.cnpq.br/4682028731610851

Flávio José de Lima Silva: Projeto Golfinho Rotador, Fernando de Noronha, PE, Brasil.

E-mail: flaviogolfinho@yahoo.com.br

Link para o currículo Lattes: http://lattes.cnpq.br/1421802360229451

Data de submissão: 28 de agosto de 2020

Data de recebimento de correções: 12 de setembro de 2020

Data do aceite: 12 de setembro de 2020

Avaliado anonimamente 